\title{
Exposure to Ambient Air Pollution and the Risk of Inflammatory Bowel Disease: A European Nested Case-Control Study
}

\author{
Jorrit L. Opstelten ${ }^{1}$ (D) Rob M. J. Beelen ${ }^{2,3} \cdot$ Max Leenders $^{2} \cdot$ Gerard Hoek $^{2}$ • \\ Bert Brunekreef $^{2}$ - Fiona D. M. van Schaik ${ }^{1}$ - Peter D. Siersema ${ }^{1,4}$. \\ Kirsten T. Eriksen ${ }^{5}$ Ole Raaschou-Nielsen ${ }^{5,6}$ - Anne Tjønneland ${ }^{5}$. \\ Kim Overvad $^{7} \cdot$ Marie-Christine Boutron-Ruault $^{8,9} \cdot$ Franck Carbonnel $^{8,9,10}$. \\ Kees de Hoogh ${ }^{11,12,13} \cdot$ Timothy J. Key $^{14} \cdot$ Robert Luben $^{15} \cdot$ Simon S. M. Chan ${ }^{16,17}$ • \\ Andrew R. Hart ${ }^{16,17} \cdot$ H. Bas Bueno-de-Mesquita ${ }^{1,18,19,20} \cdot$ Bas Oldenburg $^{1}$
}

Received: 22 March 2016/ Accepted: 7 July 2016/Published online: 26 July 2016

(c) The Author(s) 2016. This article is published with open access at Springerlink.com

\begin{abstract}
Background Industrialization has been linked to the etiology of inflammatory bowel disease (IBD).

Aim We investigated the association between air pollution exposure and IBD.

Methods The European Prospective Investigation into Cancer and Nutrition cohort was used to identify cases with Crohn's disease (CD) $(n=38)$ and ulcerative colitis (UC) $(n=104)$ and controls $(n=568)$ from Denmark, France,
\end{abstract}

H Bas Bueno-de-Mesquita and Bas Oldenburg are joint last authors.

Electronic supplementary material The online version of this article (doi:10.1007/s10620-016-4249-4) contains supplementary material, which is available to authorized users.

Bas Oldenburg

boldenbu@umcutrecht.nl

1 Department of Gastroenterology and Hepatology, University Medical Center Utrecht, P.O. Box 85500, 3508 GA Utrecht, The Netherlands

2 Institute for Risk Assessment Sciences, Utrecht University, P.O. Box 80178, 3508 TD Utrecht, The Netherlands

3 Center for Sustainability, Environment and Health, National Institute for Public Health and the Environment (RIVM), P.O. Box 1, 3720 BA Bilthoven, The Netherlands

4 Department of Gastroenterology and Hepatology, Radboud University Medical Center, P.O. Box 9101, 6500 HB Nijmegen, The Netherlands

5 Danish Cancer Society Research Center, Strandboulevarden 49, 2100 Copenhagen $\varnothing$, Denmark

6 Department of Environmental Science, Aarhus University, Frederiksborgvej 399, 4000 Roskilde, Denmark

7 Section for Epidemiology, Department of Public Health, Aarhus University, Bartholins Allé 2, 8000 Aarhus C, Denmark the Netherlands, and the UK, matched for center, gender, age, and date of recruitment. Air pollution data were obtained from the European Study of Cohorts for Air Pollution Effects. Residential exposure was assessed with land-use regression models for particulate matter with diameters of $<10 \mu \mathrm{m}\left(\mathrm{PM}_{10}\right),<2.5 \mu \mathrm{m}\left(\mathrm{PM}_{2.5}\right)$, and between 2.5 and $10 \mu \mathrm{m}\left(\mathrm{PM}_{\text {coarse }}\right)$, soot $\left(\mathrm{PM}_{2.5}\right.$ absorbance), nitrogen oxides, and two traffic indicators. Conditional logistic regression analyses were performed to calculate odds ratios (ORs) with $95 \%$ confidence intervals (CIs). Results Although air pollution was not significantly associated with $\mathrm{CD}$ or UC separately, the associations were mostly similar. Individuals with IBD were less likely to have higher exposure levels of $\mathrm{PM}_{2.5}$ and $\mathrm{PM}_{10}$, with ORs

8 Paris-Saclay University, Université Paris-Sud, Université de Versailles-Saint-Quentin-en-Yvelines (UVSQ), Centre de Recherche en Épidémiologie et Santé des Populations (CESP), U1018, Institut National de la Santé et de la Recherche Médicale (INSERM), Institut Gustave Roussy, 114 rue Edouard Vaillant, 94800 Villejuif, France

9 Institut Gustave Roussy, 114 Rue Edouard Vaillant, 94805 Villejuif, France

10 Department of Gastroenterology, Bicêtre University Hospital, Assistance Publique des Hôpitaux de Paris, 78 Rue du Général Leclerc, 94275 Le Kremlin Bicêtre, France

11 Environmental Exposure and Health Unit, Department of Epidemiology and Public Health, Swiss Tropical and Public Health Institute, Socinstrasse 57, 4051 Basel, Switzerland

12 University of Basel, Petersplatz 1, 4001 Basel, Switzerland

13 MRC-PHE Center for Environment and Health, Department of Epidemiology and Biostatistics, Imperial College London, South Kensington Campus, London SW7 2AZ, UK

14 Cancer Epidemiology Unit, Nuffield Department of Population Health, University of Oxford, Richard Doll Building, Old Road Campus, Oxford OX3 7LF, UK 
of 0.24 (95\% CI $0.07-0.81)$ per $5 \mu \mathrm{g} / \mathrm{m}^{3}$ and $0.25(95 \%$ CI $0.08-0.78)$ per $10 \mu \mathrm{g} / \mathrm{m}^{3}$, respectively. There was an inverse but nonsignificant association for $\mathrm{PM}_{\text {coarse }} \mathrm{A}$ higher nearby traffic load was positively associated with IBD [OR 1.60 (95\% CI 1.04-2.46) per 4,000,000 motor vehicles $\times \mathrm{m}$ per day]. Other air pollutants were positively but not significantly associated with IBD.

Conclusion Exposure to air pollution was not found to be consistently associated with IBD.

Keywords Air pollution - Particulate matter .

Inflammatory bowel disease · Crohn's disease $\cdot$ Ulcerative colitis

$\begin{array}{ll}\text { Abbreviations } \\ \text { CD } & \text { Crohn's disease } \\ \text { CI } & \text { Confidence interval } \\ \text { EPIC } & \begin{array}{l}\text { European Prospective Investigation into } \\ \text { Cancer and Nutrition }\end{array} \\ \text { ESCAPE } & \begin{array}{l}\text { European Study of Cohorts for Air Pollution } \\ \text { Effects }\end{array} \\ & \text { InD } \\ \text { NO } & \text { Nitrogen oxide } \\ \text { OR } & \text { Odds ratio } \\ \text { PM } & \text { Particulate matter } \\ \text { UC } & \text { Ulcerative colitis }\end{array}$

\section{Introduction}

Inflammatory bowel disease (IBD) is a disabling intestinal condition of unclear etiology affecting over two million people in Europe alone [1]. Both Crohn's disease (CD) and ulcerative colitis (UC), the two main forms of IBD, are thought to result from a complex interplay between the

15 Strangeways Research Laboratory, Institute of Public Health, University of Cambridge, Worts Causeway,

Cambridge CB1 8RN, UK

16 Department of Medicine, Faculty of Medicine and Health Sciences, Norwich Medical School, University of East Anglia, Norwich NR4 7TJ, UK

17 Department of Gastroenterology, Norfolk and Norwich University Hospital NHS Trust, Colney Lane, Norwich NR4 7UY, UK

18 Department for Determinants of Chronic Diseases, National Institute for Public Health and the Environment (RIVM), P.O. Box 1, 3720 BA Bilthoven, The Netherlands

19 Department of Epidemiology and Biostatistics, School of Public Health, Imperial College London, South Kensington Campus, London SW7 2AZ, UK

20 Department of Social and Preventive Medicine, Faculty of Medicine, University of Malaya, Jalan Universiti, 50603 Kuala Lumpur, Malaysia immune system and gut microbiota in genetically susceptible individuals [2]. Yet, the changing epidemiology of IBD supports a key role for environmental factors in the development of this chronic disorder [3].

The incidence of IBD in Western countries has increased over the last century but currently appears relatively stable, whereas a rapid disease emergence is observed in developing nations, where IBD was formerly uncommon [4, 5]. Consequently, industrialization and westernization of lifestyle have been linked to the etiology of $\mathrm{CD}$ and $\mathrm{UC}[3,6,7]$. Although various risk factors, such as diet [8], have previously been proposed, these do not fully explain the increase in the incidence of IBD and other environmental changes must therefore be involved [9].

Air pollution is associated with industrialization and consists of a complex mixture of different substances, such as particulate matter (PM). Although air pollution has mainly been associated with cardiorespiratory disorders [10], limited experimental and epidemiological data suggest that air pollutants may also exert deleterious gastrointestinal effects [11]. Potential mechanisms by which air pollutants may cause intestinal injury are thought to include direct adverse effects on epithelial cells, alterations in immune responses, or modulation of the gut microbiota [11-14].

Epidemiological studies examining the relationship between air pollution and IBD are scarce. In a case-control study from the UK, children and young adults, but not older individuals, living in areas with high-level exposure to nitrogen dioxide $\left(\mathrm{NO}_{2}\right)$ and sulfur dioxide had an increased risk of developing $\mathrm{CD}$ and $\mathrm{UC}$, respectively, indicating possible age-related effects [15]. However, this study was based on regional air pollution estimates, limiting exposure assessment. Therefore, we aimed to investigate the association between residential exposure to ambient air pollution and IBD in a nested case-control study within a multicenter European cohort. Based on previous studies, we hypothesized that air pollution exposure increases the risk of developing CD and UC.

\section{Materials and Methods}

\section{Study Population}

Subjects were identified from the European Prospective Investigation into Cancer and Nutrition (EPIC) study, a large multicenter cohort investigation designed to explore the association between lifestyle and environmental factors and chronic diseases. The methods of the main study were described previously [16]. In the present study, we made use of cases and controls drawn from a subset of this cohort, namely 227,620 initially healthy men and women recruited from five centers in Denmark, France, the Netherlands, and 
the UK between 1993 and 2000 (Table 1). At baseline, participants provided information on age, gender, habitual diet, and lifestyle factors, including smoking and physical activity, by self-administered questionnaires. Participants' height and weight were measured by trained health professionals or obtained through self-reports.

\section{Exposure Assessment}

Air pollution data were obtained from the European Study of Cohorts for Air Pollution Effects (ESCAPE). The ESCAPE project was initiated to investigate the health effects of air pollution within European countries by linking exposure data to health data from ongoing cohort studies, including EPIC [17]. The study areas of ESCAPE generally included major cities with surrounding rural areas and included large regions of the country in some cohorts (Table 1). The methods of the standardized measurement procedures were published elsewhere $[18,19]$. In summary, for each study area of ESCAPE, particulate matter with an aerodynamic diameter of $<10 \mu \mathrm{m}\left(\mathrm{PM}_{10}\right)$, particulate matter with an aerodynamic diameter of $<2.5 \mu \mathrm{m}\left(\mathrm{PM}_{2.5}\right)$, blackness of the $\mathrm{PM}_{2.5}$ exposed filter $\left(\mathrm{PM}_{2.5}\right.$ absorbance) (a marker for black carbon or soot), nitrogen oxides $\left(\mathrm{NO}_{x}\right)$ and $\mathrm{NO}_{2}$ were measured within 1 year during three different seasons between 2008 and 2011 in at least 20 sites [20, 21]. The concentration of $\mathrm{PM}_{\text {coarse }}$ was calculated as the difference between concentrations of $\mathrm{PM}_{10}$ and $\mathrm{PM}_{2.5}$. Subsequently, the annual average concentration of each pollutant was calculated. Air pollution exposure at the baseline residential address of study participants was then estimated by land-use regression models. These models were developed for each pollutant in each study area to explain the spatial variation of air pollution concentrations, taking various geographical factors into account, including altitude, population density, industrial land use, green space, and traffic flow variables. In addition to the air pollution concentrations, within ESCAPE two traffic indicators at the participant's residential address were evaluated: traffic intensity on the nearest road (vehicles per day) and total traffic load on all major roads in a 100-m buffer (sum of traffic intensity multiplied by the length of those roads). Considering that air pollution was measured after enrollment, concentrations were back-extrapolated to the baseline year of each participant according to a standardized protocol used in previous ESCAPE work [17]. Back-extrapolation was only possible for pollutants for which historical data were available.

\section{Cases and Controls}

The cohort was followed up until at least June 2004 and in some centers up to December 2009. Individuals with incident $\mathrm{CD}$ or UC were identified using population-based disease registries (Denmark, the Netherlands) or follow-up questionnaires (France, the UK). The medical reports of all potential cases were reviewed by local gastroenterologists to confirm the diagnoses and to obtain information on diagnostic investigations and disease extent. In this nested case-control analysis, each case was matched with four randomly selected unique controls for center, gender, age at recruitment ( \pm 6 months), and date of recruitment ( \pm 3 months). Controls were alive and had no CD, UC, microscopic or indeterminate colitis on the date of diagnosis of their matched case (incidence density sampling). For the present study, only cases with available air pollution estimates could be included. As the selection of controls was performed prior to the current study and the study areas of ESCAPE did not always cover the entire geographical area of the individual EPIC cohorts, air pollution measures were not available for all controls of a case.

\section{Statistical Analysis}

Continuous data were expressed as medians with percentiles, because of the skewed distribution. Categorical data were expressed as frequencies with percentages. Correlations between the individual air pollution measures and traffic indicators were assessed using the Pearson correlation coefficient. Air pollutant concentrations were divided into tertiles according to the distribution across all matched controls. Conditional logistic regression analyses were performed to determine the association between air pollution exposure and IBD. Accordingly, associations were assessed within each cohort rather than between study areas. Considering the relatively small numbers of cases, associations were studied for CD and UC separately and combined. Odds ratios (ORs) with $95 \%$ confidence intervals (CIs) were calculated to estimate the risk of IBD according to the different air pollutant concentrations and traffic indicators used as continuous and categorical variables. In a multivariable model, analyses were adjusted for smoking status (categorized into never smoker, former smoker, and current smoker) and socioeconomic status using educational level (categorized into primary school, technical school, secondary school, and higher education) as previous studies documented associations between these factors and IBD [22, 23]. All models for traffic indicators were additionally adjusted for background $\mathrm{NO}_{2}$ concentration. Trends across tertiles were computed using the median value of each tertile as a continuous variable. In sensitivity analyses, analyses were repeated for air pollutant concentrations back-extrapolated to the baseline year of participants. Twosided $p$ values below 0.05 were considered statistically significant. All analyses were performed using SPSS version 21 (IBM Corp., Armonk, NY, USA). 
Table 1 Participating centers, study areas, and characteristics of the individual cohorts

\begin{tabular}{|c|c|c|c|c|c|c|}
\hline $\begin{array}{l}\text { Country and } \\
\text { center }\end{array}$ & $\begin{array}{l}\text { Individual } \\
\text { EPIC } \\
\text { cohort }\end{array}$ & $\begin{array}{l}\text { Study area } \\
\text { ESCAPE }\end{array}$ & $\begin{array}{l}\text { Cohort } \\
\text { size }\end{array}$ & Nature of cohort & 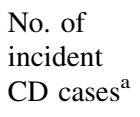 & $\begin{array}{l}\text { No. of } \\
\text { incident } \\
\text { UC cases }^{\mathrm{a}}\end{array}$ \\
\hline $\begin{array}{l}\text { Denmark, } \\
\text { Aarhus, and } \\
\text { Copenhagen }\end{array}$ & $\mathrm{DCH}$ & $\begin{array}{l}\text { Copenhagen } \\
\text { area }\end{array}$ & 57,054 & $\begin{array}{l}\text { Population-based cohort of men and women aged } \\
\text { 50-64 years. Enrollment period 1993-1997. Cases } \\
\text { identified up to July } 2007\end{array}$ & 11 & 30 \\
\hline $\begin{array}{l}\text { France, } \\
\text { regions } \\
\text { throughout } \\
\text { country }\end{array}$ & E3N & $\begin{array}{l}\text { Paris, Lyon, } \\
\text { Grenoble } \\
\text { and, } \\
\text { Marseille }\end{array}$ & 72,996 & $\begin{array}{l}\text { Female teachers and co-workers aged } 40-65 \text { years from a } \\
\text { nationwide health insurance scheme. Enrollment period } \\
\text { 1993-1997. Cases identified up to April } 2008\end{array}$ & 5 & 10 \\
\hline $\begin{array}{l}\text { The } \\
\text { Netherlands, } \\
\text { Bilthoven }\end{array}$ & MORGEN & $\begin{array}{l}\text { Large regions } \\
\text { of the } \\
\text { country }\end{array}$ & 22,715 & $\begin{array}{l}\text { Population-based cohort of men and women aged } \\
\text { 20-65 years. Enrollment period 1993-1997. Cases } \\
\text { identified up to December } 2009\end{array}$ & 9 & 27 \\
\hline $\begin{array}{l}\text { The } \\
\text { Netherlands, } \\
\text { Utrecht }\end{array}$ & Prospect & $\begin{array}{l}\text { Large regions } \\
\text { of the } \\
\text { country }\end{array}$ & 17,357 & $\begin{array}{l}\text { Women aged } 49-70 \text { years in a breast cancer screening } \\
\text { program. Enrollment period 1993-1997. Cases identified } \\
\text { up to December } 2009\end{array}$ & 7 & 14 \\
\hline $\begin{array}{l}\text { The UK, } \\
\text { Oxford }\end{array}$ & Oxford & $\begin{array}{l}\text { Large regions } \\
\text { of the } \\
\text { country }\end{array}$ & 57,498 & $\begin{array}{l}\text { Members of vegetarian societies and readers of health } \\
\text { food magazines aged 20-80 years. Enrollment period } \\
\text { 1993-2000. Cases identified up to May } 2004\end{array}$ & 6 & 23 \\
\hline Total & & & 227,620 & & 38 & 104 \\
\hline
\end{tabular}

$C D$, Crohn's disease; $D C H$, Danish Diet, Cancer and Health cohort; E3N, Etude Épidémiologique des femmes de la Mutuelle Générale de l'Education Nationale; EPIC, European Prospective Investigation into Cancer and Nutrition; ESCAPE, European Study of Cohorts for Air Pollution Effects; $U C$, ulcerative colitis

${ }^{\text {a }}$ Only incident cases (and their controls) with air pollution estimates were selected

\section{Ethical Considerations}

The original cohort studies were approved by the institutional medical ethics committees.

\section{Results}

A total of $38 \mathrm{CD}$ cases (median age at diagnosis 56.2 years, $76.3 \%$ female) and $104 \mathrm{UC}$ cases (median age at diagnosis 55.2 years, $70.2 \%$ female) with air pollution measures were identified (Table 2). The median time between recruitment and diagnosis was 4.5 years [interquartile range (IQR) 2.3-6.8 years] and 3.8 years (IQR 2.1-6.4 years) for $\mathrm{CD}$ and $\mathrm{UC}$, respectively. Fourteen $\mathrm{CD}$ cases $(36.9 \%)$ had ileal disease. Left-sided colitis (involvement limited up to the splenic flexure) was the commonest disease phenotype in UC cases $(n=45$, $43.6 \%$ ). Air pollution estimates were available for 100,90 , 83, 70, and $27 \%$ of controls from the Dutch Prospect cohort, the British cohort, the Dutch MORGEN cohort, the Danish cohort, and the French cohort, respectively. The distribution of air pollutant concentrations and traffic indicators for all IBD cases and controls per individual cohort is presented in Supplementary Tables 1-5. These tables show that within cohorts, pollution distributions were generally very similar between cases and controls and that in some cohorts, the concentration ranges of especially
$\mathrm{PM}_{2.5}$ and $\mathrm{PM}_{10}$ were very small. The correlations between these estimates are presented in Supplementary Tables 6-10.

No statistically significant associations were detected between air pollution exposure and either $\mathrm{CD}$ (Table 3 ) or UC (Table 4), apart from a positive association for total traffic load on all major roads within a 100-m buffer [OR 1.58 (95\% CI 1.00-2.49) per 4,000,000 motor vehicles $\mathrm{m}$ per day] in the crude analysis of UC. The effect sizes were largely similar for the univariable and multivariable analyses and for CD and UC. In the crude analysis of CD and UC combined, residential exposure to $\mathrm{PM}_{2.5}$ was inversely associated with IBD, with an OR of 0.28 (95\% CI $0.08-0.94$ ) per $5 \mu \mathrm{g} / \mathrm{m}^{3}$ (Table 5). A positive association was found for total traffic load on all major roads [OR 1.60 (95\% CI 1.06-2.43) per 4,000,000 motor vehicles $\times \mathrm{m}$ per day]. These associations remained statistically significant with similar effect sizes after adjusting for smoking status and educational level in the multivariable analysis. Additionally, $\mathrm{PM}_{10}$ concentrations were inversely associated with IBD in the multivariable model, with an OR of 0.25 (95\% CI $0.08-0.78$ ) per $10 \mu \mathrm{g} / \mathrm{m}^{3}$. Excluding data of the French cohort, which had the lowest proportion of IBD cases $(n=15)$ and controls with air pollution measures $(n=20)$, did not affect the direction of the effect sizes materially (data not shown). The associations for $\mathrm{PM}_{2.5}$ per cohort are presented in Supplementary Fig. 1. In the analysis based on tertiles, significant inverse associations 
were detected for $\mathrm{PM}_{2.5} \quad\left(p_{\text {trend }}=0.01\right)$ and $\mathrm{PM}_{\text {coarse }}$ $\left(p_{\text {trend }}=0.04\right)$ in IBD (Supplementary Table 11). Air pollution estimates back-extrapolated to the baseline year of each participant were generally higher than those during 2008-2011. Although no statistically significant associations were found, the sensitivity analyses for IBD for backextrapolated concentrations of $\mathrm{NO}_{2}, \mathrm{NO}_{x}, \mathrm{PM}_{2.5}$ absorbance and $\mathrm{PM}_{10}$ showed similar effect sizes as for nonback-extrapolated concentrations, apart from $\mathrm{PM}_{2.5}$ absorbance (Table 5).

\section{Discussion}

In this European multicenter study, no consistent association between residential exposure to ambient air pollution and the risk of IBD was found. The effect sizes were mostly similar for CD and UC separately. Individuals with IBD were less likely to have higher exposure levels of $\mathrm{PM}_{2.5}$ and $\mathrm{PM}_{10}$, whereas a positive association was observed for total traffic load on all major nearby roads. Other air pollutants were mostly positively but not statistically significantly associated with IBD. Although not reaching statistical significance, the effect sizes were broadly similar when back-extrapolating air pollutant concentrations to the participants' baseline year.

Numerous studies have confirmed the association of ambient air pollution with a variety of diseases, and several underlying biological mechanisms have been proposed $[10,17,24,25]$. The link between air pollution and intestinal health is, however, less well established with a few studies showing positive associations with colorectal cancer, appendicitis, and nonspecific abdominal pain [26-30]. In this respect, the adverse effects of smoking [31, 32], which may have some resemblance with air pollution, may help indicate the potential impact of air pollution exposure. It is hypothesized that exposure to air pollutants may contribute to the development of intestinal disorders, including IBD, through diverse biological mechanisms. First, ingestion of air pollutants by inhalation

Table 2 Characteristics of inflammatory bowel disease cases and controls

\begin{tabular}{|c|c|c|c|c|}
\hline & $\mathrm{CD}$ cases $(n=38)$ & Controls $(n=152)$ & UC cases $(n=104)$ & Controls $(n=416)$ \\
\hline Female, $n(\%)$ & $29(76.3)$ & $116(76.3)$ & $73(70.2)$ & $292(70.2)$ \\
\hline Age (years) at recruitment, median (IQR) & $50.9(44.7-60.9)$ & $50.3(44.5-59.0)$ & $50.7(43.2-56.1)$ & $50.9(43.2-56.6)$ \\
\hline Age (years) at diagnosis, median (IQR) & $56.2(49.7-63.6)$ & - & $55.2(48.1-60.9)$ & - \\
\hline \multicolumn{5}{|l|}{ Distribution of Crohn's disease, $n(\%)$} \\
\hline L1, ileal & $14(36.9)$ & - & - & - \\
\hline L2, colonic & $13(34.2)$ & - & - & - \\
\hline L3, ileocolonic & $10(26.3)$ & - & - & - \\
\hline$+\mathrm{L} 4$, upper gastrointestinal disease & $1(2.6)$ & - & - & - \\
\hline Unknown & $0(0.0)$ & - & - & - \\
\hline \multicolumn{5}{|l|}{ Distribution of ulcerative colitis, $n(\%)$} \\
\hline E1, ulcerative proctitis & - & - & $25(24.3)$ & - \\
\hline E2, left-sided colitis & - & - & $45(43.6)$ & - \\
\hline E3, extensive colitis & - & - & $26(25.2)$ & - \\
\hline Unknown & - & - & $7(6.8)$ & - \\
\hline \multicolumn{5}{|l|}{ Smoking status at recruitment, $n(\%)$} \\
\hline Never smoker & $13(34.2)$ & $52(34.2)$ & $36(34.6)$ & $180(43.3)$ \\
\hline Former smoker & $10(26.3)$ & $54(35.5)$ & $34(32.7)$ & $118(28.4)$ \\
\hline Current smoker & $15(39.5)$ & $44(28.9)$ & $33(31.7)$ & $116(27.9)$ \\
\hline Unknown & $0(0.0)$ & $2(1.3)$ & $1(1.0)$ & $2(0.5)$ \\
\hline \multicolumn{5}{|l|}{ Highest educational level at recruitment, $n(\%)$} \\
\hline Primary school & $4(10.5)$ & $29(19.1)$ & $15(14.4)$ & $61(14.7)$ \\
\hline Technical school & $17(44.7)$ & $38(25.0)$ & $36(34.6)$ & $128(30.8)$ \\
\hline Secondary school & $10(26.3)$ & $39(25.7)$ & $22(21.2)$ & $91(21.9)$ \\
\hline Higher education & 7 (18.4) & $45(29.6)$ & $27(26.0)$ & $116(27.9)$ \\
\hline Not specified & $0(0.0)$ & $1(0.7)$ & $4(3.8)$ & $14(3.4)$ \\
\hline Unknown & $0(0.0)$ & $0(0.0)$ & $0(0.0)$ & $6(1.4)$ \\
\hline
\end{tabular}

$C D$ Crohn's disease, IQR interquartile range, $U C$ ulcerative colitis 
Table 3 Association between air pollution exposure and Crohn's disease ( $n=38$ cases)

\begin{tabular}{llr}
\hline & \multicolumn{2}{l}{ Odds of CD } \\
\cline { 2 - 3 } & Unadjusted OR (95 \% CI) & Adjusted OR (95 \% CI) \\
\hline $\mathrm{NO}_{2}$ & $1.25(0.68-2.30)$ & $1.13(0.59-2.16)$ \\
$\mathrm{NO}_{x}$ & $1.26(0.75-2.12)$ & $1.17(0.67-2.03)$ \\
$\mathrm{PM}_{2.5}$ & $0.29(0.03-2.71)$ & $0.12(0.01-1.77)$ \\
$\mathrm{PM}_{2.5}$ absorbance & $0.59(0.11-3.03)$ & $0.34(0.04-3.05)$ \\
$\mathrm{PM}_{10}$ & $0.45(0.07-2.90)$ & $0.10(0.01-1.37)$ \\
$\mathrm{PM}_{\text {coarse }}$ & $1.07(0.17-6.55)$ & $0.59(0.07-4.98)$ \\
Traffic intensity on the nearest road & $1.18(0.82-1.70)$ & $1.16(0.79-1.71)$ \\
Traffic intensity on major roads within $100-\mathrm{m}$ buffer $^{\mathrm{b}}$ & $1.92(0.64-5.82)$ & $1.81(0.50-6.47)$ \\
\hline
\end{tabular}

ORs are presented for the following increments: $10 \mu \mathrm{g} / \mathrm{m}^{3}$ for $\mathrm{NO}_{2}, 20 \mu \mathrm{g} / \mathrm{m}^{3}$ for $\mathrm{NO}_{x}, 5 \mu \mathrm{g} / \mathrm{m}^{3}$ for $\mathrm{PM}_{2.5}, 10^{-5} \mathrm{~m}^{-1}$ for $\mathrm{PM}_{2.5}$ absorbance, $10 \mu \mathrm{g} / \mathrm{m}^{3}$ for $\mathrm{PM}_{10}, 5 \mu \mathrm{g} / \mathrm{m}^{3}$ for $\mathrm{PM}_{\text {coarse }}, 5000$ motor vehicles per day for the traffic intensity on the nearest road, 4,000,000 motor vehicles $\times \mathrm{m}$ per day for the total traffic load on all major roads within a 100 -m buffer

$C D$ Crohn's disease, $N O$ nitrogen oxide, $O R$ odds ratio, $P M$ particulate matter

a Adjusted for smoking status and educational level

b Additionally adjusted for background $\mathrm{NO}_{2}$ concentration (continuous variable)

Table 4 Association between air pollution exposure and ulcerative colitis ( $n=104$ cases)

\begin{tabular}{|c|c|c|}
\hline & \multicolumn{2}{|l|}{ Odds of UC } \\
\hline & Unadjusted OR (95\% CI) & Adjusted OR $(95 \% \mathrm{CI})^{\mathrm{a}}$ \\
\hline $\mathrm{NO}_{2}$ & $1.03(0.73-1.46)$ & $0.99(0.70-1.41)$ \\
\hline $\mathrm{NO}_{x}$ & $1.06(0.79-1.43)$ & $1.03(0.76-1.38)$ \\
\hline $\mathrm{PM}_{2.5}$ & $0.27(0.06-1.17)$ & $0.23(0.05-1.02)$ \\
\hline $\mathrm{PM}_{2.5}$ absorbance & $1.19(0.48-2.96)$ & $1.20(0.48-2.98)$ \\
\hline $\mathrm{PM}_{10}$ & $0.34(0.09-1.27)$ & $0.28(0.07-1.07)$ \\
\hline $\mathrm{PM}_{\text {coarse }}$ & $0.38(0.11-1.35)$ & $0.31(0.09-1.10)$ \\
\hline Traffic intensity on the nearest road ${ }^{\mathrm{b}}$ & $1.08(0.90-1.29)$ & $1.06(0.88-1.27)$ \\
\hline Traffic intensity on major roads within $100-\mathrm{m}$ buffer $^{\mathrm{b}}$ & $1.58(1.00-2.49)$ & $1.55(0.97-2.46)$ \\
\hline
\end{tabular}

ORs are presented for the following increments: $10 \mu \mathrm{g} / \mathrm{m}^{3}$ for $\mathrm{NO}_{2}, 20 \mu \mathrm{g} / \mathrm{m}^{3}$ for $\mathrm{NO}_{x}, 5 \mu \mathrm{g} / \mathrm{m}^{3}$ for $\mathrm{PM}_{2.5}, 10^{-5} \mathrm{~m}^{-1}$ for $\mathrm{PM}_{2.5}$ absorbance, $10 \mu \mathrm{g} / \mathrm{m}^{3}$ for $\mathrm{PM}_{10}, 5 \mu \mathrm{g} / \mathrm{m}^{3}$ for $\mathrm{PM}_{\text {coarse }}, 5000$ motor vehicles per day for the traffic intensity on the nearest road, 4,000,000 motor vehicles $\times \mathrm{m}$ per day for the total traffic load on all major roads within a 100 -m buffer

$N O$ nitrogen oxide, $O R$ odds ratio, $P M$ particulate matter, $U C$ ulcerative colitis

${ }^{a}$ Adjusted for smoking status and educational level

b Additionally adjusted for background $\mathrm{NO}_{2}$ concentration (continuous variable)

or contaminated foods may have direct toxic effects on epithelial cells, which may induce proinflammatory responses and increase gut permeability [11]. Second, various studies have shown that air pollution exposure may result in systemic inflammatory effects, such as changes in circulating cytokines, including tumor necrosis factor alpha [33]. Notably, air pollution has also been related to immunologically mediated disorders that may share some epidemiological and pathogenic aspects with IBD [34]. For instance, exposure to $\mathrm{PM}_{10}$ has been associated with an increased risk of relapse in multiple sclerosis [35], whereas traffic exposure has been found to be positively associated with incident rheumatoid arthritis [36]. Third, it is thought that air pollution may modulate the microbial composition of the gut [14], as recently exemplified in two studies in which PM exposure in mice led to significant alterations in the microbiota and induced acute and chronic intestinal inflammatory responses $[12,13]$.

To date, very few epidemiological studies explored the effects of air pollution in IBD. In a nested case-control study from the UK, in the whole population, no significant association between air pollution and incident IBD was 
Table 5 Association between air pollution exposure and inflammatory bowel disease ( $n=142$ cases)

\begin{tabular}{llr}
\hline & \multicolumn{1}{l}{ Odds of IBD } & \\
\cline { 2 - 3 } & Unadjusted OR (95 \% CI) & Adjusted OR (95\% CI) \\
\hline $\mathrm{NO}_{2}$ & $1.08(0.80-1.46)$ & $1.05(0.77-1.42)$ \\
$\mathrm{NO}_{x}$ & $1.11(0.86-1.43)$ & $1.08(0.83-1.40)$ \\
$\mathrm{PM}_{2.5}$ & $0.28(0.08-0.94)$ & $0.24(0.07-0.81)$ \\
$\mathrm{PM}_{2.5}$ absorbance & $0.99(0.45-2.17)$ & $1.03(0.45-2.34)$ \\
$\mathrm{PM}_{10}$ & $0.37(0.13-1.09)$ & $0.25(0.08-0.78)$ \\
$\mathrm{PM}_{\text {coarse }}$ & $0.52(0.19-1.45)$ & $0.42(0.14-1.20)$ \\
Traffic intensity on the nearest road & $1.07(0.92-1.26)$ \\
Traffic intensity on major roads within $100-\mathrm{m}$ buffer & \\
Back-extrapolated $\mathrm{NO}_{2}$ & $1.09(0.93-1.28)$ & $1.60(1.04-2.46)$ \\
Back-extrapolated $\mathrm{NO}_{x}$ & $1.60(1.06-2.43)$ & $1.07(0.73-1.59)$ \\
Back-extrapolated $\mathrm{PM}_{2.5}$ absorbance & $1.14(0.78-1.66)$ & $1.10(0.81-1.49)$ \\
Back-extrapolated $\mathrm{PM}_{10}$ & $1.15(0.86-1.55)$ & $0.40(0.06-2.78)$ \\
\hline
\end{tabular}

ORs are presented for the following increments: $10 \mu \mathrm{g} / \mathrm{m}^{3}$ for $\mathrm{NO}_{2}, 20 \mu \mathrm{g} / \mathrm{m}^{3}$ for $\mathrm{NO}_{x}, 5 \mu \mathrm{g} / \mathrm{m}^{3}$ for $\mathrm{PM}_{2.5}, 10^{-5} \mathrm{~m}^{-1}$ for $\mathrm{PM}_{2.5}$ absorbance, $10 \mu \mathrm{g} / \mathrm{m}^{3}$ for $\mathrm{PM}_{10}, 5 \mu \mathrm{g} / \mathrm{m}^{3}$ for $\mathrm{PM}_{\text {coarse }}, 5000$ motor vehicles per day for the traffic intensity on the nearest road, 4,000,000 motor vehicles $\times \mathrm{m}$ per day for the total traffic load on all major roads within a $100-\mathrm{m}$ buffer

$I B D$ inflammatory bowel disease, $N O$ nitrogen oxide, $O R$ odds ratio, $P M$ particulate matter

a Adjusted for smoking status and educational level

b Additionally adjusted for background $\mathrm{NO}_{2}$ concentration (continuous variable)

found [15]. However, children and young adults living in areas with higher levels (within the upper three quintiles) of $\mathrm{NO}_{2}$ and sulfur dioxide, respectively, were more likely to develop CD [OR 2.31 (95\% CI 1.25-4.28) for individuals aged $\leq 23$ years] and UC [OR $2.00(95 \%$ CI $1.08-3.72$ ) for individuals aged $\leq 25$ years]. Land-use regression models for more refined exposure assessments could not be incorporated in this study. An ecological analysis from the US related hospitalizations for IBD to air pollution emissions from an emission inventory, but was unable to estimate air pollution concentrations [37]. In our study, which included mainly middle aged to elderly people, we observed opposing associations. This could indicate that different pollutants have differential effects in specific groups. For example, younger people (with a developing immune system) might be more susceptible to air pollutants as compared to older people. Importantly, children and young adults are also likely to spend more time outdoors and near their home, which may increase and better reflect true personal exposure. Exposure assessment may therefore be more accurate in these individuals. There were no statistically significant associations for $\mathrm{CD}$ and $\mathrm{UC}$ separately, which presumably resulted from the relatively small numbers of cases. Disease-specific results may exist, as previously observed, for example, in the opposing associations for smoking between $\mathrm{CD}$ and UC [22], although the effect sizes were mostly similar for both forms of IBD in our study. We observed inverse associations for some pollutants, which appeared largely consistent across centers and in the analyses using pollution exposure as continuous and categorical variables. It remains unclear whether these associations reflect a true causal relationship or that these pollutants are a proxy for other variables. Interestingly, in the earlier mentioned study, $\mathrm{PM}_{10}$ and $\mathrm{NO}_{2}$ concentrations were inversely associated with $\mathrm{CD}$ in individuals aged $44-57$ years with ORs of 0.48 (95\% CI $0.29-0.80$ ) and 0.56 (95\% CI 0.33-0.95), respectively [15], demonstrating that inverse associations have previously been observed in older patients in another population using a different methodological approach. Overall, despite previous data suggesting that air pollutants may negatively impact IBD, no coherent associations have currently been confirmed to draw firm conclusions on the putative adverse effects of air pollution exposure in $\mathrm{CD}$ and $\mathrm{UC}$, indicating the need for further research.

This study had several strengths. First, the multicenter design enabled us to explore the association between air pollution and IBD in several European countries. Second, a significant advantage over previous studies was the use of land-use regression models to accurately determine smallscale variations in residential exposure to air pollution and traffic intensity for each participant according to a highly standardized protocol. Third, both cases and controls were drawn from the same baseline population, thereby reducing the risk of selection bias. Fourth, to ensure case ascertainment all diagnoses were confirmed by local physicians 
and participants with indeterminate or microscopic colitis were excluded. Fifth, the number of cases was similar to what was expected, which reduces the likelihood of followup bias [38].

Despite nesting in a well-characterized cohort, the limited sample size was an important drawback and our study may have been underpowered to detect statistical differences. Therefore, we chose to evaluate outcomes for CD and UC separately and for total IBD. Furthermore, air pollution estimates were assessed only at the residential address of each participant and not, for example, at their working address, where individuals may also be exposed. This could have resulted in misclassification of exposure. Moreover, air pollution was measured after diagnosis, which was a general issue in epidemiological studies using ESCAPE exposure data, such as in a previous study linking air pollution to mortality [17]. However, previous studies show that spatial air pollution contrasts remain stable over long periods of time and are well predicted with land-use regression models [39-43]. Using back-extrapolation, we evaluated the association for some pollutants at the baseline year of each participant, with effect sizes being broadly similar to the main analyses. It has been estimated that most of the participants did not move after enrollment [17], but exact data on moving were unavailable for all centers. The majority of cases developed IBD over the age of 50 years, indicating late-onset IBD, whereas CD and UC commonly present at an earlier age. This limited the opportunity to study age-specific effects, and the results may therefore not be generalizable to the whole IBD population as other phenotypes may have different environmental influences. Considering the limited sample size and multiple comparisons, we cannot entirely exclude that our results are due to chance findings. Finally, although we were able to either match or adjust for potential confounders, such as center and smoking, residual confounding (by unknown risk factors) could not be fully excluded in this observational study.

To conclude, we were unable to demonstrate a consistent association between residential exposure to ambient air pollution and IBD risk in this European multicenter cohort.

Acknowledgments J.L.O. was supported by an unrestricted research grant from Dr. Falk Pharma. The coordination of the European Prospective Investigation into Cancer and Nutrition (EPIC) study was financially supported by the European Commission (DG-SANCO) and the International Agency for Research on Cancer (IARC). The national cohorts were supported by the Danish Cancer Society (Denmark); Ligue contre le Cancer, Institut Gustave Roussy, Mutuelle Générale de l'Education Nationale, French Institute of Health and Medical Research (INSERM) (France); Dutch Ministry of Health, Welfare and Sports, Dutch Prevention Funds, LK Research Funds, Dutch ZON (Zorg Onderzoek Nederland), World Cancer Research Fund (WCRF), Statistics Netherlands (the Netherlands); Cancer Research UK C8221/A19170, Medical Research Council
MR/M012190/1 (UK). The European Study of Cohorts for Air Pollution Effects (ESCAPE) study has received funding from the European Community's Seventh Framework Program (FP7/2007-2011) under Grant Agreement No. 211250.

Authors' contributions J.L.O., R.M.J.B., H.B.B.-d-M., and B.O were involved in conception and design. J.L.O., R.M.J.B., G.H., B.B., F.D.M.vS., P.D.S., K.T.E., O.R.-N., A.T., K.O., M.-C.B.-R., F.C., K.dH., T.J.K., R.L., S.S.M.C., A.R.H., H.B.B.-d-M., and B.O were involved in acquisition of the data. J.L.O., R.M.J.B., M.L., G.H., B.B., B.O were involved in analysis and interpretation of the data. J.L.O was involved in drafting of the manuscript. All authors were involved in critical revision of the manuscript for important intellectual content and gave final approval of the submitted manuscript.

\section{Compliance with ethical standards}

Conflict of interest The authors have no conflicts of interest to disclose.

Open Access This article is distributed under the terms of the Creative Commons Attribution 4.0 International License (http://crea tivecommons.org/licenses/by/4.0/), which permits use, duplication, adaptation, distribution and reproduction in any medium or format, as long as you give appropriate credit to the original author(s) and the source, provide a link to the Creative Commons license and indicate if changes were made.

\section{References}

1. Burisch J, Jess T, Martinato M, Lakatos PL. The burden of inflammatory bowel disease in Europe. $J$ Crohns Colitis. 2013;7:322-337.

2. Scharl M, Rogler G. Inflammatory bowel disease pathogenesis: what is new? Curr Opin Gastroenterol. 2012;28:301-309.

3. Ng SC, Bernstein CN, Vatn MH, et al. Geographical variability and environmental risk factors in inflammatory bowel disease. Gut. 2013;62:630-649.

4. Thia KT, Loftus EV Jr, Sandborn WJ, Yang SK. An update on the epidemiology of inflammatory bowel disease in Asia. Am J Gastroenterol. 2008;103:3167-3182.

5. Molodecky NA, Soon IS, Rabi DM, et al. Increasing incidence and prevalence of the inflammatory bowel diseases with time, based on systematic review. Gastroenterology. 2012;142:46-54.

6. Bernstein CN, Shanahan F. Disorders of a modern lifestyle: reconciling the epidemiology of inflammatory bowel diseases. Gut. 2008;57:1185-1191.

7. Soon IS, Molodecky NA, Rabi DM, Ghali WA, Barkema HW, Kaplan GG. The relationship between urban environment and the inflammatory bowel diseases: a systematic review and metaanalysis. BMC Gastroenterol. 2012;12:51.

8. Hou JK, Abraham B, El-Serag H. Dietary intake and risk of developing inflammatory bowel disease: a systematic review of the literature. Am J Gastroenterol. 2011;106:563-573.

9. Ananthakrishnan AN. Environmental risk factors for inflammatory bowel diseases: a review. Dig Dis Sci. 2015;60:290-298.

10. Brunekreef B, Holgate ST. Air pollution and health. Lancet. 2002;360:1233-1242.

11. Beamish LA, Osornio-Vargas AR, Wine E. Air pollution: an environmental factor contributing to intestinal disease. J Crohns Colitis. 2011;5:279-286.

12. Kish L, Hotte N, Kaplan GG, et al. Environmental particulate matter induces murine intestinal inflammatory responses and alters the gut microbiome. PLoS One. 2013;8:e62220. 
13. Salim SY, Jovel J, Wine E, et al. Exposure to ingested airborne pollutant particulate matter increases mucosal exposure to bacteria and induces early onset of inflammation in neonatal IL-10deficient mice. Inflamm Bowel Dis. 2014;20:1129-1138.

14. Salim SY, Kaplan GG, Madsen KL. Air pollution effects on the gut microbiota: a link between exposure and inflammatory disease. Gut Microbes. 2014;5:215-219.

15. Kaplan GG, Hubbard J, Korzenik J, et al. The inflammatory bowel diseases and ambient air pollution: a novel association. Am J Gastroenterol. 2010;105:2412-2419.

16. Riboli E, Hunt KJ, Slimani N, et al. European Prospective Investigation into Cancer and Nutrition (EPIC): study populations and data collection. Public Health Nutr. 2002;5:1113-1124.

17. Beelen R, Raaschou-Nielsen O, Stafoggia M, et al. Effects of long-term exposure to air pollution on natural-cause mortality: an analysis of 22 European cohorts within the multicentre ESCAPE project. Lancet. 2014;383:785-795.

18. Eeftens M, Beelen R, de Hoogh K, et al. Development of land use regression models for $\mathrm{PM}_{2.5}, \mathrm{PM}_{2.5}$ absorbance, $\mathrm{PM}_{10}$ and $\mathrm{PM}_{\text {coarse }}$ in 20 European study areas; results of the ESCAPE project. Environ Sci Technol. 2012;46:11195-11205.

19. Beelen R, Hoek G, Vienneau D, et al. Development of $\mathrm{NO}_{2}$ and $\mathrm{NO}_{x}$ land use regression models for estimating air pollution exposure in 36 study areas in Europe-the ESCAPE project. Atmos Environ. 2013;72:10-23.

20. Cyrys J, Eeftens M, Heinrich J, et al. Variation of $\mathrm{NO}_{2}$ and $\mathrm{NO}_{x}$ concentrations between and within 36 European study areas: results from the ESCAPE study. Atmos Environ. 2012; 62:374-390.

21. Eeftens M, Tsai M-Y, Ampe C, et al. Spatial variation of $\mathbf{P M}_{2.5}$, $\mathrm{PM}_{10}, \mathrm{PM}_{2.5}$ absorbance and $\mathrm{PM}_{\text {coarse }}$ concentrations between and within 20 European study areas and the relationship with $\mathrm{NO}_{2}-$ results of the ESCAPE project. Atmos Environ. 2012;62:303-317.

22. Mahid SS, Minor KS, Soto RE, Hornung CA, Galandiuk S. Smoking and inflammatory bowel disease: a meta-analysis. Mayo Clin Proc. 2006;81:1462-1471.

23. Aamodt G, Jahnsen J, Bengtson MB, Moum B, Vatn MH. Geographic distribution and ecological studies of inflammatory bowel disease in southeastern Norway in 1990-1993. Inflamm Bowel Dis. 2008;14:984-991.

24. Mills NL, Donaldson K, Hadoke PW, et al. Adverse cardiovascular effects of air pollution. Nat Clin Pract Cardiovasc Med. 2009;6:36-44.

25. Langrish JP, Bosson J, Unosson J, et al. Cardiovascular effects of particulate air pollution exposure: time course and underlying mechanisms. J Intern Med. 2012;272:224-239.

26. Calvert GM, Ward E, Schnorr TM, Fine LJ. Cancer risks among workers exposed to metalworking fluids: a systematic review. Am J Ind Med. 1998:33:282-292.

27. García-Pérez J, López-Cima MF, Pérez-Gómez B, et al. Mortality due to tumours of the digestive system in towns lying in the vicinity of metal production and processing installations. Sci Total Environ. 2010;408:3102-3112.

28. Kaplan GG, Dixon E, Panaccione R, et al. Effect of ambient air pollution on the incidence of appendicitis. CMAJ. 2009; 181:591-597.
29. Orazzo F, Nespoli L, Ito K, et al. Air pollution, aeroallergens, and emergency room visits for acute respiratory diseases and gastroenteric disorders among young children in six Italian cities. Environ Health Perspect. 2009;117:1780-1785.

30. Kaplan GG, Szyszkowicz M, Fichna J, et al. Non-specific abdominal pain and air pollution: a novel association. PLoS One. 2012;7:e47669.

31. Silverstein MD, Lashner BA, Hanauer SB, Evans AA, Kirsner JB. Cigarette smoking in Crohn's disease. Am J Gastroenterol. 1989;84:31-33.

32. Botteri E, Iodice S, Bagnardi V, Raimondi S, Lowenfels AB, Maisonneuve P. Smoking and colorectal cancer: a meta-analysis. JAMA. 2008;300:2765-2778.

33. van Eeden SF, Tan WC, Suwa T, et al. Cytokines involved in the systemic inflammatory response induced by exposure to particulate matter air pollutants (PM(10)). Am J Respir Crit Care Med. 2001;164:826-830.

34. Cohen R, Robinson D Jr, Paramore C, Fraeman K, Renahan K, Bala M. Autoimmune disease concomitance among inflammatory bowel disease patients in the United States, 2001-2002. Inflamm Bowel Dis. 2008;14:738-743.

35. Oikonen M, Laaksonen M, Laippala P, et al. Ambient air quality and occurrence of multiple sclerosis relapse. Neuroepidemiology. 2003;22:95-99.

36. Hart JE, Laden F, Puett RC, Costenbader KH, Karlson EW. Exposure to traffic pollution and increased risk of rheumatoid arthritis. Environ Health Perspect. 2009;117:1065-1069.

37. Ananthakrishnan AN, McGinley EL, Binion DG, Saeian K. Ambient air pollution correlates with hospitalizations for inflammatory bowel disease: an ecologic analysis. Inflamm Bowel Dis. 2011;17:1138-1145.

38. Shivananda S, Lennard-Jones J, Logan R, et al. Incidence of inflammatory bowel disease across Europe: is there a difference between north and south? Results of the European Collaborative Study on Inflammatory Bowel Disease (EC-IBD). Gut. 1996;39:690-697.

39. Beelen R, Hoek G, Fischer P, van den Brandt PA, Brunekreef B. Estimated long-term outdoor air pollution concentrations in a cohort study. Atmos Environ. 2007;41:1343-1358.

40. Eeftens M, Beelen R, Fischer P, Brunekreef B, Meliefste K, Hoek G. Stability of measured and modelled spatial contrasts in $\mathrm{NO}_{2}$ over time. Occup Environ Med. 2011;68:765-770.

41. Cesaroni G, Porta D, Badaloni C, et al. Nitrogen dioxide levels estimated from land use regression models several years apart and association with mortality in a large cohort study. Environ Health. 2012;11:48.

42. Wang R, Henderson SB, Sbihi H, Allen RW, Brauer M. Temporal stability of land use regression models for traffic-related air pollution. Atmos Environ. 2013;64:312-319.

43. Gulliver J, de Hoogh K, Hansell A, Vienneau D. Development and back-extrapolation of $\mathrm{NO}_{2}$ land use regression models for historic exposure assessment in Great Britain. Environ Sci Technol. 2013;47:7804-7811. 